\title{
Properties of microfibrillar cellulose filled thermoplastic natural rubber: Morphology, mechanical properties, and melt flow index
}

\author{
Ihda Novia Indrajati*, Indiah Ratna Dewi, Dwi Wahini Nurhajati \\ Center for Leather, Rubber and Plastics, Ministry of Industry Republic of Indonesia \\ J1. Sokonandi No. 9 Yogyakarta, 55166, Indonesia \\ *Coresponding author. Tel. +62 274 512929, Fax. +62 274563655 \\ E-mail: i-novia@kemenperin.go.id
}

Submitted: 5 October 2020

Revised: 7 December 2020

Accepted: 11 December 2020

\begin{abstract}
Microfibrillar cellulose (MFC) was derived from local pineapple leaf fiber (PALF) and employed as filler in thermoplastic natural rubber (TPNR), that was a blend of natural rubber (NR) and polypropylene (PP). The blends were prepared by dynamic vulcanization. The performance of MFC-filled TPNR on morphology, mechanical properties, aging behavior, and melt flow index (MFI) were evaluated in this study. MFC was synthesized through several processing steps, including extraction, bleaching, acid hydrolysis, and ball-milling mechanical treatment. The blends were made in a fixed ratio of $60 / 40$ (NR/PP) with various fiber concentration. NR/PP was blended in Rheomix internal mixer at $160^{\circ} \mathrm{C}$ for 15 minutes with turning rotor of $90 \mathrm{rpm}$. The results showed that the particle size distribution of MFC was rather broad with some web-like agglomerates. An improvement in tensile strength was observed at low fiber loading. Fiber improved tear strength, but decreased elongation at break as expected. The obtained hardness was independent to fiber loading. The fractured sample of TPNR showed fibrous morphology indicating plastic deformation. MFC decreased the melt flow index of TPNR. The MFI value ranges between 3-5 $\mathrm{g} / 10 \mathrm{~min}$. Introduction $1 \mathrm{phr}$ of MFC resulted in ultimate mechanical properties with considerable melt flow.
\end{abstract}

Keywords: cellulose, natural rubber, pineapple leaf fiber, reinforcement, thermoplastic elastomer.

\section{INTRODUCTION}

Thermoplastic elastomer (TPE) is a class of polymer that combines processing properties of thermoplastic with the functional performance of rubber. It can be processed in conventional thermoplastic molding machines, but remains elastic characteristic of rubber. TPE offers many advantages compared to conventional rubber, such as rapid fabrication and better material utilization, because of recyclability property (Pechurai et al., 2008; Sae-Oui et al., 2010). TPE can be prepared through simple blend which results in thermoplastic elastomer polyolefin (TPO), and crosslinked elastomeric phase which results in thermoplastic vulcanizate (TPV). TPV differs from simple TPE blends because of their morphological structure. TPV contains crosslinked rubber phase which is finely dispersed in continuous thermoplastic matrix. Dynamic vulcanization is the most common process to prepare the TPV. It is the selective crosslinking process of rubber phase during melt mixing with a thermoplastic material under high shear and deformation rate. Thus, phase inversion takes place from rubber matrix phase to dispersed crosslinked rubber particles, whereas the thermoplastic phase turns into a continuous matrix. Among various types of thermoplastic that commonly used, polypropylene (PP) is the most extensive one. PP has unique properties, including high melting temperature, low density, high chemical solvent resistance, as well as heat resistance. Meanwhile, high heat resistance rubbers are used for TPV preparation, such as ethylene propylene diene monomer (EPDM) and ethylene propylene monomer (EPM). Nowadays, the use of natural rubber (NR) is gained much attention since it offers excellent mechanical properties over those of synthetic rubber (Chaouki Bendjaouahdou \& Bensaad, 2018; Mondal et al., 2013). The blend of NR and polyolefins is well- 
known as thermoplastic natural rubber (TPNR).

Extensive research has been conducted on the development of TPNR (Abdelmouleh et al., 2007; Anandhan \& Bhowmick, 2013; Benmesli \& Riahi, 2014; Bukit \& Frida, 2014; Indrajati et al., 2018; Kahar et al., 2017; Kalapakdee \& Amornsakchai, 2014; Miedzianowska et al., 2019). However, it has not been yet commercialized because of its low technical specifications (Bahruddin et al., 2012). TPNR involves the mixing of two materials with different polarity and solubility. The incompatibility of two phases will result in low mechanical properties. Therefore, the challenges of the development of TPNR are centered on how to obtain good phases interaction and homogeneous crosslinked rubber particles distribution within thermoplastic matrix. Introduction filler or compatibilizer into the blends may be overcome this weak interaction (C. Bendjaouahdou \& Bensaad, 2013). Furthermore, filler not only improve adhesion between two phases, but also impart mechanical properties and other characteristics. In general, fillers are incorporated into polymer matrix either in the form of particulates or fibers. In comparison to particulate filler, short fiber offers many advantages in reinforcing polymer matrices because of its high stretch to weight ratio, adjustable (high-low) strain modulus, good mechanical and thermal properties, greater design flexibility, and ease of processing. The reinforcement of short fiber is affected by fiber content, aspect ratio (L/D), fiber orientation, and interfacial adhesion between fiber and matrix (Kalapakdee \& Amornsakchai, 2014; Shibulal \& Naskar, 2011). Environmental concern has brought a lot of attention in employing bioderived material in polymer industries. Cellulose from natural fiber is being an attractive bioderived material that is widely studied because of its outstanding properties and renewable sources.

Various types of cellulose can be altered from the basic raw cellulose, including nanocrystalline cellulose (NCC), micro-fibrillated cellulose (MFC), or nano-fibrillated cellulose (NFC), depending on the preparation method and sources (Jia et al., 2013). Even studied extensively, however, its application in polymer field is relatively new (Siró \& Plackett, 2010). Many researches, on application of cellulosic fiber in thermoplastic elastomer, have been conducted recently (Anuar \& Zuraida, 2011; Abdelmouleh et al., 2007; Salmah \& Ismail, 2008). Pineapple leaf fiber (PALF) is one of cellulosic fiber that has been promising as substitution to synthetic fiber. The outstanding properties of PALF is correlated to its high alpha cellulose content $(70-82 \%)$, low micro fibrillar angle $\left(14^{\circ}\right)$, and high degree of crystallinity (Asim et al., 2015; Suwanruji et al., 2017). PALF also has specific modulus and strength close to glass fiber (Yuakkul et al., 2015). Moreover, PALF is abundant and an inexpensive material because it is mostly as agricultural waste. Several researchers have been reported various studies on the application of PALF in polymer matrices. Prukkaewkanjana et al. (2015) has been successfully employed PALF in NBR matrix, and revealed that the effect of PALF dominates in low strain. Suwanruji et al. (2017) exhibited the improvement of LDPE and PP properties by the addition of modified-PALF. Kalapakdee and Amornsakchai (2014), and Yuakkul et al. (2015) have employed PALF-based filler in simple thermoplastic elastomer matrix. They observed an improvement on mechanical properties by fiber addition. However, even though extensive researches in this area have been carried out, but only few studies employed PALF in dynamic crosslinked-TPNR.

Previous study has successfully developed the TPNR from NR and PP blends using PALF derived-MFC as reinforcement (Indrajati et al., 2018). Thermal properties of the resulted TPNR had been deeply discussed. In this present study, the effect of MFC concentration on mechanical properties and melt flow of NR/PP blends will be discussed in details. Scanning electron micrograph has been conducted to observe either the fiber or the blends morphology. Characterization of the resulted fiber was also made to support the detailed discussion.

\section{MATERIALS AND METHODS Materials}

The raw PALF was supplied by local producer (Subang, West Java), in the form of $0.5 \mathrm{~cm}$-cut. Sodium hydroxide $(\mathrm{NaOH})$, sodium hypochlorite $(\mathrm{NaOCl})$, sulfuric acid $\left(\mathrm{H}_{2} \mathrm{SO}_{4}\right) 98 \%$, and acetic acid glacial $\left(\mathrm{CH}_{3} \mathrm{COOH}\right) 96 \%$ were purchased in PT. Brataco Indonesia. All of these reagents were industrial grade. Standard Indonesian Rubber (SIR) 10 was supplied by PT. Perkebunan Nusantara IX. Polypropylene Trilene HI10HO (injection molding grade, MFI $\left(230{ }^{\circ} \mathrm{C} / 2.16 \mathrm{~kg}\right) 10 \mathrm{~g} / \mathrm{min}$ from PT. Chandra Asri. The rubber additives 
Table 1. NR compound composition.

\begin{tabular}{lr}
\hline \multicolumn{1}{c}{ Ingredients } & Concentration (phr) \\
\hline SIR & 100.0 \\
ZnO & 5.0 \\
Aflux 42 & 1.5 \\
HAF black (N-330) & 20.0 \\
GPF black (N-660) & 15.0 \\
MACO & 5.0 \\
TMQ & 2.0 \\
6PPD & 1.0 \\
CBS & 1.2 \\
Sulfur & 1.0 \\
PVI & 0.1 \\
\hline
\end{tabular}

included active zinc oxide ( $\mathrm{ZnO})(\mathrm{PT}$. Brataco Indonesia), Aflux $42 \mathrm{M}$ processing promotor (Rhein Chemie), HAF black N-330 (OCI Korea), GPF black N-660 (OCI Korea), antioxidant 2,2,4Trimethyl-1,2-Dihydroquinoline (TMQ) (Kemai), antiozonant N-(1,3-Dimethylbutyl)-N'-phenyl-pphenylenediamine (6PPD) (Northeast), accelerator N-Cyclohexylbenzothiazole-2-Sulfenamide (CBS) (Northeast), Sulfur SP-325 (Miwon), and Pilgard PVI Pre-vulcanization Inhibitor. Maleated castor oil (MACO) was used as plasticizer which is prepared as in our previous work (Indrajati \& Dewi, 2017).

\section{Microfibrillar Cellulose (MFC) Preparation}

The microfibrillar cellulose (MFC) was prepared from $0.5 \mathrm{~cm}$-cut dried PALF, in accordance to the previous published protocol (Indrajati et al., 2018). The detailed procedure was the cut-PALF was, first, grinded in a crusher. The following step was fiber purification in order to obtain pure cellulose. The grinded-fibers were mercerized in $10 \%(\mathrm{w} / \mathrm{w})$ aqueous sodium hydroxide $(\mathrm{NaOH})$ at room temperature for $18 \mathrm{~h}$. The fiber to liquor (FL) ratio was maintained to 1:30 for this treatment. Afterwards, the treatedfiber (TF) were filtered, and washed with water several times until $\mathrm{pH}=7$, and finally air-dried overnight. Second step was delignification (bleaching) using $1 \%(\mathrm{v} / \mathrm{v})$ sodium hypochlorite $(\mathrm{NaOCl})$. The treatment was performed at $70{ }^{\circ} \mathrm{C}$ for $4 \mathrm{~h}$ under mechanical stirring at $300 \mathrm{rpm}$, and the FL ratio was kept at 1:70. After finished, the fibers were filtered and washed with water for 3 times to remove excess bleaching agent. The TF was then left to dry overnight in room temperature. MFC was obtained by hydrolysis and mechanical treatment of the cellulose. Hydrolysis was carried out in $20 \%(\mathrm{v} / \mathrm{v})$ sulfuric acid $\left(\mathrm{H}_{2} \mathrm{SO}_{4}\right)$ and FL ratio 1:50. The treatment was performed at $80{ }^{\circ} \mathrm{C}$ for $2 \mathrm{~h}$ under mechanical stirring at 500 $\mathrm{rpm}$. To stop the hydrolysis reaction, suspension was filtered immediately, and solid fraction was washed with cold tap water. The solid fraction was then air-dried overnight. The hydrolyzed fiber was treated mechanically using ball-mill to enhance the MFC properties. This treatment was carried out in acidic atmosphere $(1 \%$ acetic acid glacial) at room temperature for $2 \mathrm{~h}$. The surface speed of the ball mill was maintained to $60 \mathrm{rpm}$. Ceramic balls with various diameter were used as grinding media. After milling, the suspension was then centrifuged for 10 minutes at $3000 \mathrm{rpm}$. Solid fraction (MFC) was removed from suspension and then washed three times to remove excess acetic acid. The solid was let to dry overnight at room temperature. The particle size of resulted MFC was characterized using NIMBUS particle size analyzer with ultrasound.

\section{Thermoplastic Natural Rubber (TPNR) Preparation}

The TPNR samples were prepared by dynamic vulcanization (melt mixing) in accordance to the previous published work (Indrajati et al., 2018). NR was first compounded with its additives using two roll mill laboratory scale following the formulation on Table 1. The concentration of the compound ingredients was expressed in the term of phr (part hundred rubber). The NR compound

Table 2. TPNR formulation.

\begin{tabular}{|c|c|c|c|c|c|c|}
\hline \multirow{2}{*}{ Ingredients } & \multicolumn{6}{|c|}{ Composition (phr) } \\
\hline & PN0 & PN1 & PN2 & PN3 & PN4 & PN5 \\
\hline NR compound & 60.0 & 60.0 & 60.0 & 60.0 & 60.0 & 60.0 \\
\hline PP & 40.0 & 40.0 & 40.0 & 40.0 & 40.0 & 40.0 \\
\hline MFC & & 1.0 & 5.0 & 10.0 & 15.0 & 20.0 \\
\hline Stearic acid & 1.0 & 1.0 & 1.0 & 1.0 & 1.0 & 1.0 \\
\hline PP-g-MA & 1.0 & 1.0 & 1.0 & 1.0 & 1.0 & 1.0 \\
\hline Antioxidant & 0.5 & 0.5 & 0.5 & 0.5 & 0.5 & 0.5 \\
\hline
\end{tabular}


was rest for $24 \mathrm{~h}$ before blending process.

The NR/PP blends were performed in a Rheomix Polylab 3000 OS with $300 \mathrm{~cm}^{3}$ mixing chamber. Fill factor was chosen to be $80 \%$. The ratio of $\mathrm{NR} / \mathrm{PP}$ was kept constant at $60 / 40$, while MFC concentration was varied ranging from $0-20 \mathrm{phr}$. The detailed composition of the blends was listed on Table 2. The melt mixing was conducted at 160 ${ }^{\circ} \mathrm{C}$ with rotor running at $90 \mathrm{rpm}$. First, PP was melted at $160^{\circ} \mathrm{C}$ until achieving constant torque. Immediately, MFC was added into melted PP and mixed until the torque remained stable. The last was the NR compound addition. One cycle mixing proceeded at least 17 minutes. The resulted blends were crushed and pelleted for subsequent processes.

\section{Morphological Characterization}

Morphological of raw PALF, resultant MFC, and TPNR samples (tensile fractured) were captured using the scanning electron microscope (SEM-SNE $3200 \mathrm{M}$ ) which was operated with an accelerating voltage of $20 \mathrm{kV}$ and emission current of $100 \mu \mathrm{A}$. Prior to examination, the sample was sputter coated with gold to increase surface conductivity.

\section{Mechanical Testing}

Tensile strength and elongation at break of TPNR samples were tested using a dumbbell shaped specimen which was obtained by compression molding. The test was carried out

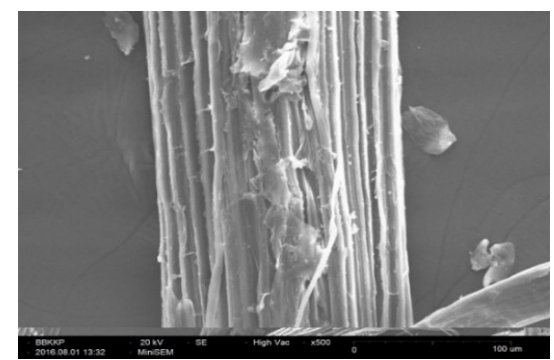

(a)

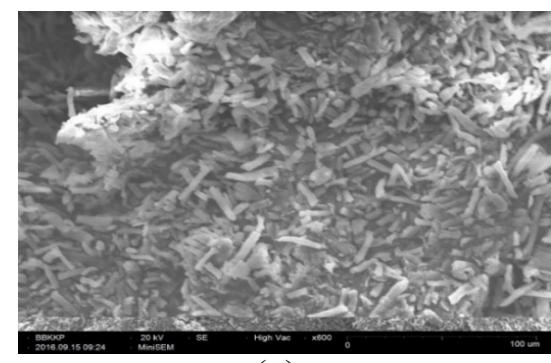

(c) according to ASTM D 412 on a universal testing machine Tinius Olsen $\mathrm{H} 25 \mathrm{~K}$ with cross head speed of $50 \mathrm{~mm} / \mathrm{min}$. The specimens were cut from a slab prepared by compression molding at $160{ }^{\circ} \mathrm{C}$ for 17 minutes, followed by cooling for 7 minutes. The pressure applied was $150 \mathrm{~kg} / \mathrm{cm}^{2}$. Hardness of TPNR were tested using Mitutoyo Shore A Durometer. Tear strength was tested according to ASTM D 624-00 using V-shaped specimen. The test was carried out in five measurements for each sample, and the average of them was determined. The mechanical properties are measured for before and after aging. Accelerated aging was performed at $100{ }^{\circ} \mathrm{C}$ for $72 \mathrm{~h}$ in an air circulated oven. The retention value of each mechanical property was calculated using equation (1).

Retention $=\frac{\text { value of aged }}{\text { value of unaged }} \times 100 \%$

\section{Melt Flow Properties}

Melt flow of TPNR was measured using melt flow indexer Tinius Olsen MP 1200 according to ASTM D 1238-10. The sample was extruded at $250{ }^{\circ} \mathrm{C}$ for 10 minutes under a load of $5 \mathrm{~kg}$. Three measurements were made for each sample and the averaged value was determined.

\section{RESULTS AND DISCUSSION Characterization of MFC}

SEM photomicrograph on Figure 1 compares the un- and treated fiber. It is shown that structural changes of the fiber have taken place after

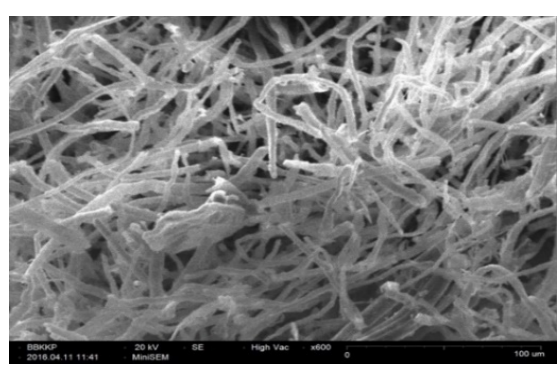

(b)

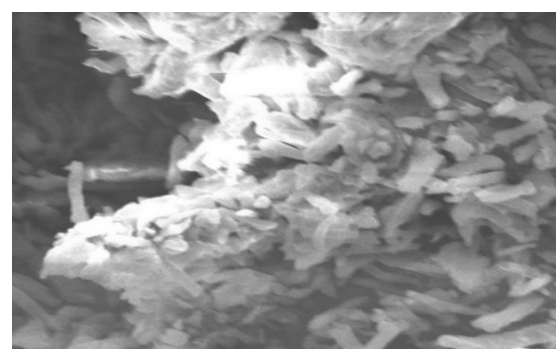

(d)

Figure 1. SEM photomicrograph of untreated PALF (a), alkali-treated (b), resulted MFC (c), agglomerate fiber (d). 


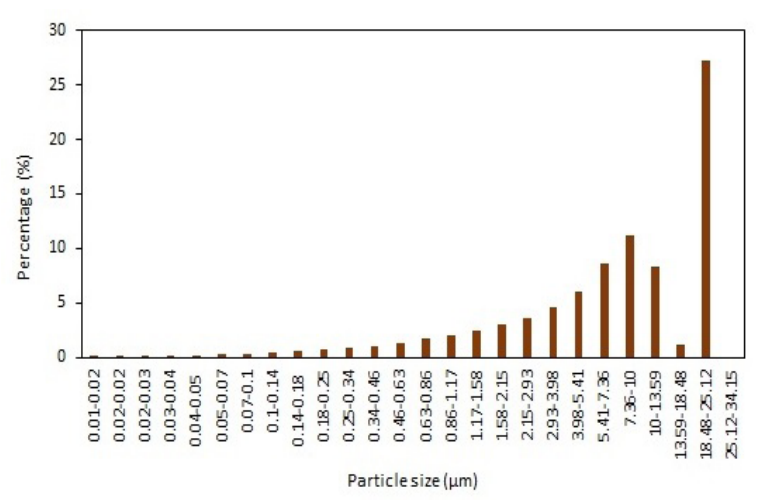

Figure 2. Particle size distribution of produced MFC.

treatments. The untreated PALF (Figure 1a) exhibits typical lignocellulosic fiber. The cellulose chains are strongly bonded together by the cementing material consisting of hemicellulose, lignin and pectin, forming a compact fiber bundle structure. The average diameter of this fiber bundle is about $120-125 \mu \mathrm{m}$.

Figure $1 \mathrm{~b}$ clearly shows the defibrillation of fiber bundle that occurred after alkali treatment. Cementing materials are dissolved by alkali resulting in loose fibers. Alkali treatment also increases the surface roughness of the fiber which facilitates mechanical interlocking with the polymer matrix (Panyasart et al., 2014). Further treatments resulted in a rod type microfibril (Figure 1c). The diameter and length of the fiber significantly reduced after these treatments. It is visually seen that the produced MFC does not have uniform size. Fiber agglomerates are also found in the form of web-like structure (Figure 1d). Web-like structure is a result of lateral aligning of microfibril with many layers. Each layer may has different amount of laterally bonded microfibril (Peng et al., 2012). This is probably resulted from hydrophilic nature of cellulose fiber. Hydroxyl groups $(-\mathrm{OH})$ presents on the fiber surface strongly interact each other lead to agglomerate formation (Siró \& Plackett, 2010). Agglomerated fiber could also be formed as a result of incorrect drying process during isolation (Huntley et al., 2015; Peng et al., 2012). Particle size analysis (Figure 2) has confirmed this finding. The distribution particle is rather broad. Small particle size $(<10$ $\mu \mathrm{m})$ dominates, but larger particles $(>10 \mu \mathrm{m})$ also presents in a marked number. Larger particle is associated to agglomerated fibers that is mentioned earlier. Actually, there is no exact definition related to the size of cellulose microfibril. Several authors mention that the thickness of MFC could be varied depends on the fiber sources. It is usually ranging between $3-10 \mathrm{~nm}$, but it is typically in the range of 20-40 $\mathrm{nm}$ because it often consists of cellulose microfibril aggregates (Siró \& Plackett, 2010). Another author reported that resulted MFC had diameter below $100 \mathrm{~nm}$ (Janardhnan \& Sain, 2006). Within this perspective, our results are still in the range.

\section{Morphology of TPNR}

Surface morphology of cross-section molded TPNR and tensile fracture samples are carried out to investigate the fiber-matrix interaction. Figure 3 shows SEM photomicrograph of those samples, on the left side is molded sample, while tensile fracture sample in on the right side. Generally, all molded samples shows homogenous phase of the NR/PP blends. MFC is embedded into the polymer matrix tightly. Tough some parts of fiber are pulled out, but the other parts are still attached in the matrix. The attached part indicates good interaction between fiber and matrix. Tensile fracture samples exhibit fibrous morphology compared to molded samples (before tensile experiment). It is perhaps related to the plastic deformation that occurred during strain.

\section{Mechanical Properties of TPNR}

The behavior of tensile and tear strength of the TPNR samples are depicted in Figure 4. Tensile strength tends to decrease upon MFC loading. A slight improvement is observed at low concentration (1 phr), but further addition tends to decrease it, even lower than of control ( $0 \mathrm{phr})$. Several authors also reported similar finding (Anuar et al., 2008; Homkhiew et al., 2018, Shibulal \& Naskar, 2011). The reduction of tensile strength could be contributed from interaction of NR-PP phase because of immiscible blend nature, and NR/PP-fiber interaction. Poor interfacial interaction between fiber-polymer matrix is the main reason for the decreasing tensile strength observed in this study. When the samples undergo stretching to a certain degree during tensile testing, if the interfacial interaction is weak, the fibers are getting pulled out at the interface. This pulled-out fiber creates voids in the matrix and leads to an ineffective stress transfer from matrix to fiber. It will result in a reduction of the tensile strength. Though some parts of fiber are still attached to the 

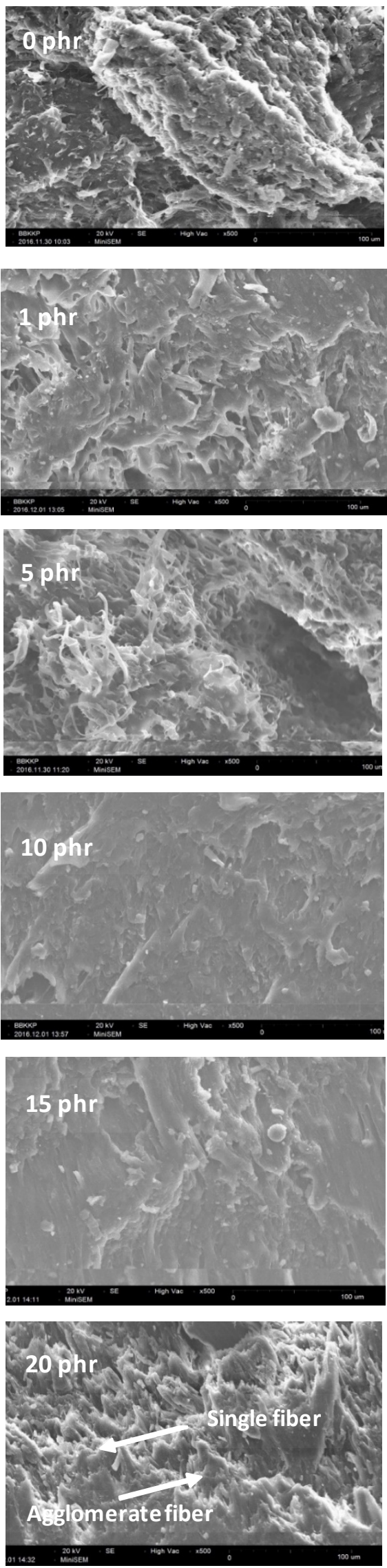

(a)

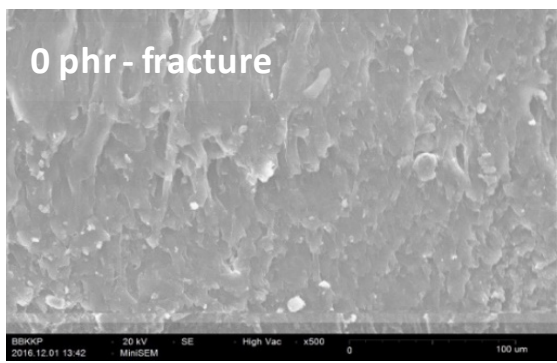

(b)

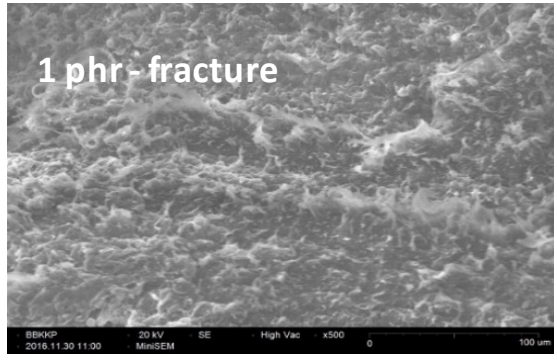

(d)

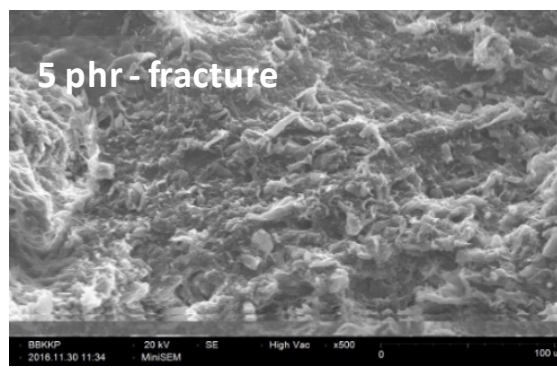

(e)

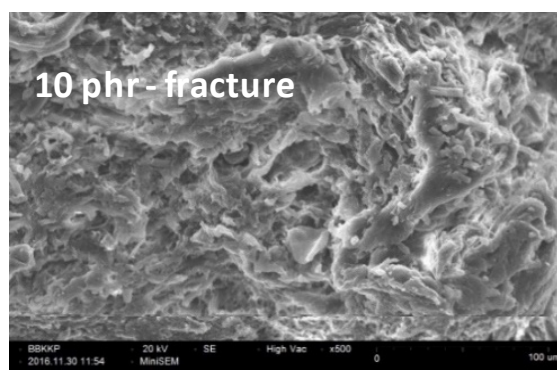

(f)
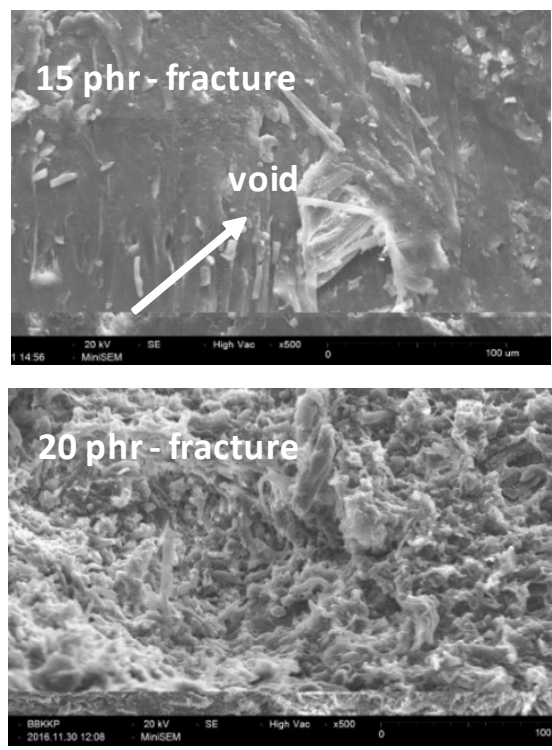

Figure 3. SEM micrograph of molded-samples (left column) and tensile fractured-samples (right column). 


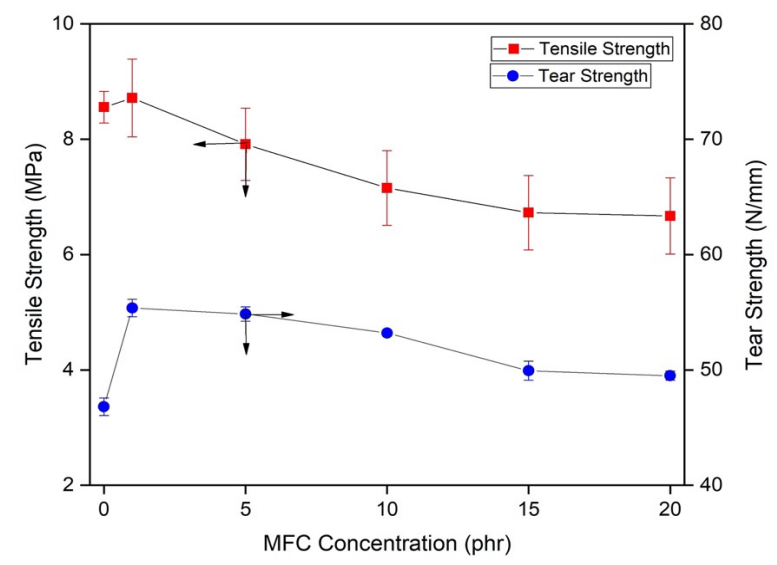

Figure 4. Tensile and tear strength of TPNR on various MFC loading.

matrix as seen in Figure 3, but probably the degree of mechanical interlocking between fiber surface and matrix is not sufficient to resist the stress applied. Furthermore, web-like agglomerates of fiber (Figure 3) contribute to poor dispersion of fiber in the matrix and resist them from being wetted evenly by the hydrophobic matrix. The fiber-fiber bonding is weaker than of fiber-matrix, and is easily broken with applied stress. Thus, resulting in lower tensile strength.

Tear strength is greatly improved with the introduction of $1 \mathrm{phr}$ MFC into the matrix (Figure 4 ), but it continues to decrease upon further fiber addition. According to Prukkaewkanjana et al. (2015), the improvement of tear strength can be attributed either from the increase of tensile strength or the change of tear process character. Fibers form a barrier that limiting the damage by hindering the crack propagation. Random fiber distribution has altered the angles of the tearing force, and increase the stress needed to overcome them. In contrast, when the fibers are in ordered pattern that is arranged in accordance to the tear direction, will propagate the crack and in turns decrease the total resistance to tearing (Miedzianowska et al., 2019; Soltani et al., 2014). Nevertheless, increasing fiber loading caused tear strength to decrease. Perhaps, it is correlated to poor fiber-matrix bonding caused by fiber agglomeration. Fiber debonding due to forces acted in the sample may accelerate the crack propagation, then in turn will decrease the tear strength.

The variation of hardness with MFC loading is exhibited on Figure 5. It is evidence that gradual

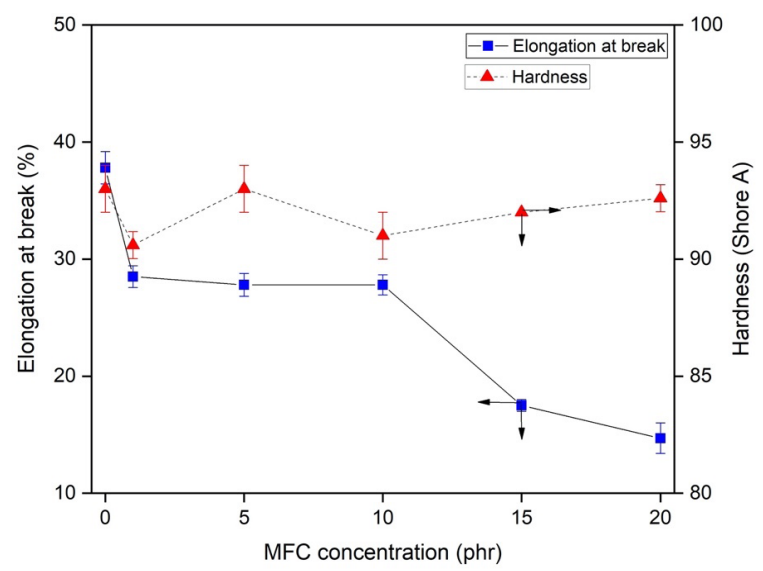

Figure 5. Elongation at break and hardness of TPNR on various MFC loading.

increase of fiber does not make any significant changes on hardness. It is ranging from $92-94$ Shore A which is much higher than of conventional rubber. Varghese et al. (2004) reported similar value for NR/PP blend (60/40 phr). They explained constant hardness was as a result of melt blending and subsequent molding processes. At the melt temperature, viscosity of PP is lower compared to rubber phase thus forming a continuous phase. The resulted morphology of NR/PP blend perhaps looks like a sea-island structure. Crosslinked NR phase is embedded in continuous PP phase. Hardness is governed by the PP phase and thus depended on the amount of PP phase. In this study, the amount of PP is constant in all the samples leading to an almost constant hardness.

Elongation at break, an index of elasticity of the blends, shows a marked reduction by the addition of fiber (Figure 5). Fibers embedded in matrix restricts the polymer chain movement, thus decreases the elongation at break. Increasing the fiber loading led to decrease the elongation at break because the hindrance of chain movement is higher.

\section{Aging Properties}

Figure 6 exhibits the retention of the mechanical properties after thermal aging. It is clearly seen that thermal aging greatly influences the mechanical properties of TPNR. The retention of tensile strength tends to increase at higher MFC loading, while tear strength and elongation at break are reduced as noticed from the retention value below $100 \%$. Meanwhile, thermal aging does not 


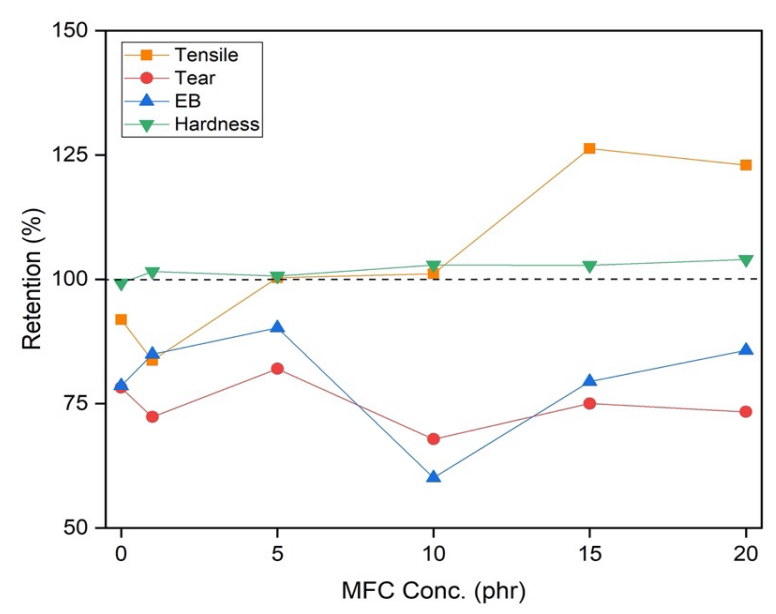

Figure 6. Retention of some mechanical properties after aging.

cause significant changes on hardness.

In TPNR system, apparent degradation is contributed from both phases, thermoplastics and rubber. Both NR and PP contain abundant $\mathrm{C}=\mathrm{C}$ double bonds on their backbone that are susceptible to heat and oxygen attack. Antioxidant is usually added into the system to delay the polymer degradation. There is a competition reaction between antioxidant and rubber with oxygen. Antioxidant should have higher reactivity with oxygen than of the rubber, so it will react first until its amount is diminished. In this point, the rubber is then started to react with oxygen. This explains temporary protection of antioxidant in polymer. Though crosslinked NR particles are in and surrounded by thermoplastic matrix, but they are still susceptible from heat and oxygen attack from the environment. The thermo-oxidative degradation is not only occurred at the main rubber chain, but also at the sulfuric crosslinks. Double protection of antioxidant is used in this system, even though antioxidant has been added into the system, but it does not provide permanent protection. Competition reaction is occurred between oxygen or heat and polymer. Antioxidant usually has faster reaction rate with oxygen compared to those of with rubber. Therefore, oxygen will react first with antioxidant until it is diminished, then continued with the polymer. In this study, although antioxidant has been added in both NR compound and TPNR system, but it does not sufficient to resist the thermo-oxidative degradation.

Typically, thermal aging on polymers

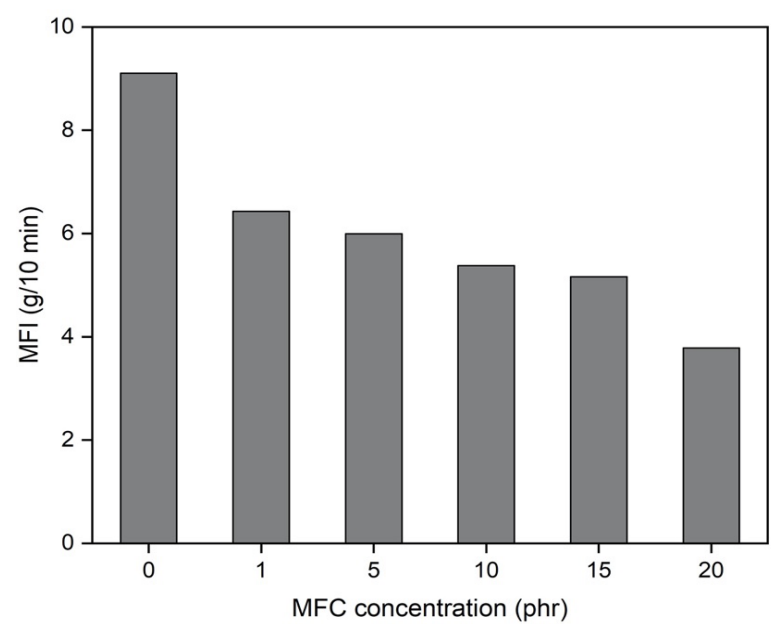

Figure 7. Melt flow index on various MFC concentration under $5 \mathrm{~kg}$ load at $250{ }^{\circ} \mathrm{C}$.

causes two main reaction, i.e. chain scission or crosslinking, which alters their properties. These reactions are competing reaction, and occurred simultaneously during aging test. Heat induces double bonds or crosslink breaking to generate free radicals. Then, free radical is reacted with oxygen to form a peroxy-radical which in turn abstract a hydrogen atom from another bond in the chain, resulting in hydroperoxide radical. The hydroperoxide splits into two radicals, and abstract hydrogen atom from other bond or polymer chain as reaction continued. The reactions are terminated by two ways, radical recombination (crosslinking) or chain scission. Radical recombination leads to polymer embrittlement and cracking, while chain scission causes deleterious effect on mechanical properties. Moreover, the ductility of the polymer matrix will be shifted to a lower value. The unreacted crosslinking agent also contributes to the formation of excessive crosslinking, or even known as post-curing (Bendjaouahdou \& Bensaad, 2018; Manaila et al., 2018). Increasing tensile strength retention indicates the domination of excessive crosslinking to occur during the aging process. Higher MFC loading probably causes more crosslinking with prolong heating on aging process. Thus, it needs more energy for breaking the matrix. Increasing crosslinking causes embrittlement and crack. When the length of two crosslinks points is decrease, the mobility of molecular chains is hindered, and finally polymer matrix becomes brittle. It is noticed by the low retention of elongation at break. Fortunately, excessive crosslinking does not significantly 
increase hardness after thermal aging.

\section{Melt Flow of TPNR Samples}

Melt flow index (MFI) gives rough description about polymer processing behavior, even though the actual condition may differ from the test condition. MFI is related to the flow characteristic of the polymer. Figure 7 shows the MFI values of the TPNR on various MFC loading.

It is evidence that MFC greatly affects the MFI value. A marked reduction is observed by incorporating $1 \mathrm{phr}$ of MFC. In filled-TPNR samples, flow of polymer is affected not only by degree of crosslinking in rubber phase, but also the filler loading. In this experiment we assume that the degree of crosslinking is similar because the basic NR compound has the same composition one to another. Fiber embedded in polymer matrix will cause hindered flow, thus reducing the polymer flow. Increasing fiber loading led to rise the hindrance and results in decreasing the MFI. Significant reduction is observed at $20 \mathrm{phr}$ fiber loading. A reduction of MFI is a sign of the enhanced interfacial interaction of the rubber and thermoplastic phases. In other word, no phase separation is occurred (Varghese et al., 2004). Perhaps, compatibilizer PP-g-MA added into the system plays a big role in resulting good interaction between NR and PP phases. This support the decreasing of tensile strength of un-aged samples is mainly due to the incorporation of MFC.

\section{CONCLUSION}

The mechanical properties and melt flow index of the TPNR were studied with respect of MFC loading. The MFC was synthesized from local PALF through several treatments, including alkali treatment, bleaching, acid hydrolysis, and ball-mill mechanical treatment. The resultant MFC had broad particle distribution. Web-like fiber agglomerates were found as a result of hydrogen bonding interaction between fibers. Incorporation of fiber influenced the mechanical properties of TPNR samples. An improvement of tensile strength was observed at low fiber loading (1 phr), but increasing fiber loading tended to decrease it. Interestingly, fiber addition caused an increase of tear strength, but further addition leads to decrease it. Hardness seemed to be independent on fiber loading, but elongation at break was reduced along with increasing fiber loading. MFC affected the melt flow of the samples by providing the hindrance to the movement. In this study, $1 \mathrm{phr}$ MFC gave ultimate mechanical properties with considerable melt flow. Considering these results, MFC is promising to be applied in thermoplastic natural rubber. Some improvements should be taken in the future related to the isolation and blending process in order to obtain ultimate mechanical properties and melt flow characteristic.

\section{ACKNOWLEDGEMENTS}

The authors are grateful to the Ministry of Industry Republic of Indonesia for financial support. The authors also want to thankful to Dr. Shinta Virdhian (Metal Industries Development Center, Bandung, Indonesia) for supporting compounding process, also to Prof. Evvy Kartini for full paper guidance.

\section{REFERENCES}

Abdelmouleh, M., Boufi, S., Belgacem, M. N., \& Dufresne, A. (2007). Short natural-fibre reinforced polyethylene and natural rubber composites: Effect of silane coupling agents and fibres loading. Composites Science and Technology, 67(7-8), 1627-1639. https://doi.org/10.1016/j. compscitech.2006.07.003

Anandhan, S., \& Bhowmick, A. K. (2013). Thermoplastic vulcanizates from post consumer computer plastics/nitrile rubber blends by dynamic vulcanization. Journal of Material Cycles and Waste Management, 15(3), 300-309. https://doi. org/10.1007/s10163-012-0112-7

Anuar, H., Wan Busu, W. N., Ahmad, S. H., \& Rasid, R. (2008). Reinforced thermoplastic natural rubber hybrid composites with Hibiscus cannabinus, L and short glass fiber - Part I: Processing parameters and tensile properties. Journal of Composite Materials, 42(11), 1075-1087. https:// doi.org/10.1177/0021998308090450

Anuar, H., \& Zuraida, A. (2011). Improvement in mechanical properties of reinforced thermoplastic elastomer composite with kenaf bast fibre. Composites Part B: Engineering, 42(3), 462-465. https://doi.org/10.1016/j. compositesb.2010.12.013

Asim, M.,Abdan, K., Jawaid, M., Nasir, M., Dashtizadeh, Z., Ishak, M. R., \& Hoque, M. E. (2015). A review on pineapple leaves fibre and its composites. International Journal of Polymer Science, 2015, 1-17. https://doi.org/10.1155/2015/950567

Bahruddin, Ahmad, A., Prayitno, A., \& Satoto, R. (2012). Morphology and mechanical properties of palm based fly ash reinforced dynamically vulcanized natural rubber/polypropylene blends. Procedia Chemistry, 4, 146-153. https://doi.org/ 
DOI 10.1016/j.proche.2012.06.021

Bendjaouahdou, C., \& Bensaad, S. (2013). The effects of organoclay on the morphology and balance properties of an immiscible polypropylene/natural rubber blend. Energy Procedia, 36, 574-590. https://doi.org/10.1016/j.egypro.2013.07.066

Bendjaouahdou, C., \& Bensaad, S. (2018). Aging studies of a polypropylene and natural rubber blend. International Journal of Industrial Chemistry, 9(4), 345-352. https://doi.org/10.1007/s40090018-0163-2

Benmesli, S., \& Riahi, F. (2014). Dynamic mechanical and thermal properties of a chemically modified polypropylene/natural rubber thermoplastic elastomerblend.PolymerTesting,36,54-61.https:// doi.org/10.1016/j.polymertesting.2014.03.016

Bukit, N., \& Frida, E. (2013). The effect zeolite addition in natural rubber polypropylene composite on mechanical, structure, and thermal characteristics. Makara Journal of Technology, 17(3), 113-120. https://doi.org/10.7454/mst.v17i3.2926

Homkhiew, C., Rawangwong, S., Boonchouytan, W., Thongruang, W., \& Ratanawilai, T. (2018). Composites from thermoplastic natural rubber reinforced rubberwood sawdust: Effects of sawdust size and content on thermal, physical, and mechanical properties. International Journal of Polymer Science, 2018, 1-11. https://doi. org/10.1155/2018/7179527

Huntley, C. J., Crews, K. D., Abdalla, M. A., Russell, A. E., \& Curry, M. L. (2015). Influence of strong acid hydrolysis processing on the thermal stability and crystallinity of cellulose isolated from wheat straw. International Journal of Chemical Engineering, 2015, 1-11. https://doi.org/10.1155/2015/658163

Indrajati, I. N., \& Dewi, I. R. (2017). Performance of maleated castor oil based plasticizer on rubber: rheology and curing characteristic studies. IOP Conference Series: Materials Science and Engineering, 223, 012001. https://doi. org/10.1088/1757-899X/223/1/012001

Indrajati, I. N., Dewi, I. R., \& Nurhajati, D. W. (2018). Thermal properties of thermoplastic natural rubber reinforced by microfibrillar cellulose. IOP Conference Series: Materials Science and Engineering, 432, 012038. https://doi. org/10.1088/1757-899X/432/1/012038

Janardhnan, S., \& Sain, M. M. (2006). Isolation of cellulose microfibrils - An enzymatic approach. Bioresources, 1(2), 176-188.

Jia, X., Chen, Y., Shi, C., Ye, Y., Wang, P., Zeng, X., \& Wu, T. (2013). Preparation and characterization of cellulose regenerated from phosphoric acid. Journal of Agricultural and Food Chemistry, 61(50), 12405-12414. https://doi.org/10.1021/ jf4042358

Kahar, A. W. M., Sarifuddin, N., \& Ismail, H. (2017).
Structural, thermal and physico-chemical properties of high density polyethylene/natural rubber/modified cassava starch blends. Iranian Polymer Journal, 26, 149-159. https://doi. org/10.1007/s13726-017-0507-3

Kalapakdee, A., \& Amornsakchai, T. (2014). Mechanical properties of preferentially aligned short pineapple leaf fiber reinforced thermoplastic elastomer: Effects of fiber content and matrix orientation. Polymer Testing, 37, 36-44. https:// doi.org/10.1016/j.polymertesting.2014.04.008

Manaila, E., Stelescu, M. D., \& Craciun, G. (2018). Degradation studies realized on natural rubber and plasticized potato starch based eco-composites obtained by peroxide cross-linking. International Journal of Molecular Sciences, 19(10), 2862. https://doi.org/10.3390/ijms19102862

Miedzianowska, J., Masłowski, M., \& Strzelec, K. (2019). Thermoplastic elastomer biocomposites filled with cereal straw fibers obtained with different processing methods - Preparation and properties. Polymers, 11(4), 641. https://doi. org/10.3390/polym 11040641

Mondal, M., Gohs, U., Wagenknecht, U., \& Heinrich, G. (2013). Polypropylene/natural rubber thermoplastic vulcanizates by eco-friendly and sustainable electron induced reactive processing. RadiationPhysicsandChemistry, 88,74-81.https:// doi.org/10.1016/j.radphyschem.2013.03.021

Panyasart, K., Chaiyut, N., Amornsakchai, T., \& Santawitee, O. (2014). Effect of surface treatment on the properties of pineapple leaf fibers reinforced polyamide 6 composites. Energy Procedia, 56, 406-413. https://doi.org/10.1016/j. egypro.2014.07.173

Pechurai, W., Nakason, C., \& Sahakaro, K. (2008). Thermoplastic natural rubber based on oil extended NR and HDPE blends: Blend compatibilizer, phase inversion composition and mechanical properties. Polymer Testing, 27(5), 621-631. https://doi. org/10.1016/j.polymertesting.2008.04.001

Peng, Y., Gardner, D. J., \& Han, Y. (2012). Drying cellulose nanofibrils: In search of a suitable method. Cellulose, 19, 91-102. https://doi. org/10.1007/s10570-011-9630-z

Prukkaewkanjana, K., Thanawan, S., \& Amornsakchai, T. (2015). High performance hybrid reinforcement of nitrile rubber using short pineapple leaf fiber and carbon black. Polymer Testing, 45, 76-82. https:// doi.org/10.1016/j.polymertesting.2015.05.004

Sae-Oui, P., Sirisinha, C., Sa-nguanthammarong, P., \& Thaptong, P. (2010). Properties and recyclability of thermoplastic elastomer prepared from natural rubberpowder(NRP)andhighdensity polyethylene (HDPE). Polymer Testing, 29(3), 346-351. https:// doi.org/10.1016/j.polymertesting.2009.12.010

Salmah, H., \& Ismail, H. (2008). The Effect of filler 
loading and maleated polypropylene on properties of rubberwood filled polypropylene/natural rubber composites. Journal of Reinforced Plastics and Composites, 27(16-17), 1867-1876. https://doi. org/10.1177/0731684407081382

Shibulal, G. S., \& Naskar, K. (2011). RFL coated aramid short fiber reinforced thermoplastic elastomer: Mechanical, rheological and morphological characteristics. Journal of Polymer Research, 18, 2295-2306. https://doi.org/10.1007/s10965-0119643-1

Siró, I., \& Plackett, D. (2010). Microfibrillated cellulose and new nanocomposite materials: A review. Cellulose, 17, 459-494. https://doi.org/10.1007/ s10570-010-9405-y

Soltani, S., Naderi, G., \& Mohseniyan, S. (2014). Mechanical, morphological and rheological properties of short nylon fiber reinforced acrylonitrile-butadiene rubber composites. Fibers and Polymers, 15, 2360-2369. https://doi. org/10.1007/s12221-014-2360-8

Suwanruji, P., Tuechart, T., Smitthipong, W., \& Chollakup, R. (2017). Modification of pineapple leaf fiber surfaces with silane and isocyanate for reinforcingthermoplastic.JournalofThermoplastic Composite Materials, 30(10), 1344-1360. https:// doi.org/10.1177/0892705716632860

Varghese, S., Alex, R., \& Kuriakose, B. (2004). Natural rubber-isotactic polypropylene thermoplastic blends. Journal of Applied Polymer Science, 92(4), 2063-2068. https://doi.org/10.1002/app.20077

Yuakkul, D., Amornsakchai, T., \& Saikrasun, S. (2015). Effect of maleated compatibilizer on anisotropic mechanical properties, thermo-oxidative stability and morphology of styrenic based thermoplastic elastomer reinforced with alkali-treated pineapple leaf fiber. International Journal of Plastics Technology, 19, 388-411. https://doi.org/10.1007/ s12588-016-9132-9 
